\title{
Efeito do silício nas concentrações de lignina e de açúcares em bainhas de folhas de arroz infectadas por Rhizoctonia solani
}

\author{
Daniel Augusto Schurt ( $\left.{ }^{1}\right)$; Fabrício Ávila Rodrigues ( $\left.{ }^{1 *}\right)$; Jorge Luiz Colodette (²); Vivian Carré-Missio ( ${ }^{1}$ ) \\ (') Universidade Federal de Viçosa (UFV), Departamento de Fitopatologia, Laboratório da Interação Planta-Patógeno, \\ Av. P. H. Rolfs, s/n, 36571-000 Viçosa (MG), Brasil \\ (2) UFV, Departamento de Engenharia Florestal, Laboratório de Celulose, Av. P. H. Rolfs, s/n, 36571-000 Viçosa (MG), Brasil \\ $\left({ }^{*}\right)$ Autor correspondente: fabricio@ufv.br
}

Recebido: 17/jun./2013; Aceito: 11/set./2013

\section{Resumo}

A queima das bainhas, causada pelo fungo Rhizoctonia solani Kühn, é uma das mais importantes doenças que afetam a produção de arroz no mundo. Este trabalho teve como objetivo verificar o efeito do silício (Si) nas concentrações de lignina solúvel e insolúvel e de açúcares totais em bainhas de folhas de arroz infectadas por R. solani. Plantas de arroz dos cultivares BR-Irga-409 e Labelle foram cultivadas em solução nutritiva sem (0 mM) ou com (2 mM) Si. A concentração de Si nas bainhas das folhas das plantas dos cultivares BR-Irga-409 e Labelle supridas com Si aumentou em 77\% e 84\%, respectivamente, em relação às plantas não supridas com Si. O comprimento relativo da lesão de queima das bainhas foi significativamente menor nas bainhas das plantas supridas com Si em relação às bainhas das plantas não supridas com esse elemento. Não houve efeito do Si e nem da inoculação com $R$. solani nas concentrações de mananas, galactanas, arabinanas, xilanas, glucanas e de açúcares totais nas bainhas das plantas dos dois cultivares. Para as plantas dos dois cultivares supridas com Si, a concentração de açúcares totais foi menor quando comparada com a dos dois cultivares na ausência de Si. Não houve variação na concentração de lignina insolúvel, solúvel e total entre os cultivares. As concentrações de lignina insolúvel e total foram maiores nas plantas supridas com Si, independentemente da inoculação com R. solani. Em conclusão, plantas de arroz supridas com Si foram mais resistentes à queima das bainhas devido a uma maior lignificação dos tecidos das bainhas e menor concentração de açúcares totais.

Palavras-chave: escleródios, nutrição mineral, Oryza sativa L., patógeno de solo, queima das bainhas.

\section{Effect of silicon on lignin and sugar concentrations of leaf sheaths in rice plants infected by Rhizoctonia solani}

\begin{abstract}
Sheath blight, caused by the fungus Rhizoctonia solani Kühn, is the major disease affecting rice production worldwide. This study aimed to verify the effect of silicon (Si) on the concentrations of soluble and insoluble lignin and sugars in the leaf sheaths of rice plants infected by R. solani. Rice plants from cultivars BR-Irga-409 and Labelle were grown in nutrient solution without or with Si (2 mM). As compared to plants non-supplied with Si, the Si concentration in leaf sheaths in cultivars BR-Irga-409 and Labelle supplied with Si increased by $77 \%$ and $84 \%$, respectively. The relative lesion length of sheath blight was significantly lower in plants supplied with Si compared to non-supplied plants. There was no effect of Si or inoculation with $R$. solani on the concentrations of mannans, galactans, arabinans, xylans, glucans and sugars in the sheaths of plants from both cultivars. There was no variation in the concentrations of insoluble, soluble and total lignin between the cultivars. The concentrations of total and insoluble lignin were higher on plants supplied with Si regardless of inoculation with $R$. solani. In conclusion, the rice plants supplied with Si were more resistant to sheath blight due to an increase in the lignifications of the leaf sheath tissues and the lower concentration of total sugars.
\end{abstract}

Keywords: sclerotia, mineral nutrition, Oryza sativa, soilborne pathogen, sheath blight. 


\section{INTRODUÇÃO}

A queima das bainhas causada por Rhizoctonia solani Kühn [Thanatephorus cucumeris (A. B. Frank) Donk] é uma das principais doenças fúngicas do arroz (Oryza sativa L.) em todo o mundo (Ou, 1985). As plantas são infectadas quando os escleródios entram em contato com as bainhas, germinam, e o micélio forma inúmeras almofadas de infecção na superfície delas (DATH, 1990), originando lesôes circulares e/ou arredondadas, de coloraçáo acinzentada e com bordas marrom-escuras (Ou, 1985). Ao coalescerem, as lesóes causam a seca parcial ou total das bainhas e das folhas, o acamamento das plantas, uma maior porcentagem de glumas vazias e uma redução no número de perfilhos (RusH e LEE, 1992). O uso da irrigaçáo por inundação, da rotaçáo da cultura com a soja e o uso de cultivares altamente produtivos têm contribuído para a ocorrência de epidemias severas de queima das bainhas, resultando na redução da produção de grãos (Bedendo e Prabhu, 2005).

O silício ( $\mathrm{Si}$ ) aumenta a resistência do arroz a diversas doenças fúngicas, tais como a brusone, a mancha parda, a queima das bainhas e a escaldadura (DATnOFF et al., 2007). Plantas de arroz de diferentes cultivares supridas com Si e inoculadas em diferentes estádios de crescimento apresentaram redução na intensidade da queima das bainhas (Rodrigues et al., 2001; 2003a,b). A concentração foliar de Si em arroz pode chegar a $10 \mathrm{dag} \mathrm{kg}^{-1}$ (Dallagnol et al., 2009), sendo superior à concentraçáo de alguns macronutrientes como o nitrogênio, o fósforo e o potássio (DATNOFF et al., 2007). O Si é absorvido pelas raízes das plantas na forma de ácido monosilícico, sendo transportado, passivamente, via fluxo da transpiração e depositado abaixo da cutícula, formando uma dupla camada sílica-cutícula (SANGSTER et al., 2001; Yoshida et al., 1962). De acordo com Kim et al. (2002), essa dupla camada sílica formada abaixo da cutícula atrasou a penetração de Pyricularia grisea nas folhas de arroz (KIm et al., 2002). Schurt et al. (2012) observaram que a resistência das bainhas de plantas supridas com $\mathrm{Si}$ à infecção por $R$. solani foi explicada pela maior resistência física decorrente da deposiçấo desse elemento.

Os açúcares desempenham um papel importante na resistência das plantas infectadas por patógenos por participarem da biossíntese de aminoácidos e ácidos graxos (SMEEKENS, 2000; VIDHYASEKARAN, 1988). A concentração de açúcares nos tecidos de uma determinada espécie de planta pode torná-la mais ou menos suscetível a uma determinada doença (VidHYASEKARAN, 1988). Na condição de baixa concentração de açúcares, as doenças causadas por patógenos necrotróficos são favorecidas (VANDERPLANK, 1984). Para os patógenos biotróficos é preciso ocorrer uma maior concentração de açúcares nos tecidos infectados (VAnderplank, 1984). Para a podridão das raízes causada por $R$. solani, a maior concentração de açúcares no hipocótilo e nas raízes das plântulas contribuiu para uma maior severidade da doença (VIDHYASEKARAN, 1988). Entretanto, a concentração de açúcares totais está relacionada com a temperatura do ambiente, pois para temperaturas menores que $15^{\circ} \mathrm{C}$ a concentraçáo de açúcares aumenta e para temperaturas superiores a $20^{\circ} \mathrm{C}$ ocorre uma diminuiçáo na concentraçáo e, consequentemente, uma reduçáo na agressividade de alguns patógenos (VIDHYASEKARAN, 1988). A produção e difusão de toxinas não seletivas e de enzimas líticas produzidas por alguns patógenos são afetadas negativamente pela maior concentração de açúcares nos tecidos infectados (VidHYASEKARAN, 1988).

A lignina desempenha função importante na resistência das plantas ao ataque por patógenos por promover o fortalecimento da parede celular (HatField e Vermerris, 2001). A composição química da bainha de uma planta de arroz é heterogênea e complexa e varia muito conforme a parte da planta analisada (Jin e CHEN, 2006) e também conforme o cultivar (Summers et al., 2003). Para a maioria das espécies de plantas cultivadas, a concentração de lignina na parede celular e na lamela média pode variar de $10 \mathrm{dag} \mathrm{kg^{-1 }}$ a $30 \mathrm{dag} \mathrm{kg}^{-1}$ (Hon e SHIRAISHI, 2001).

Este trabalho teve como objetivo verificar se as concentraçóes de lignina solúvel e insolúvel e de açúcares totais seriam potencializadas pelo $\mathrm{Si}$ nas bainhas das plantas de arroz supridas com esse elemento, contribuindo, assim, para um aumento na resistência à infecçáo por $R$. solani.

\section{MATERIAL E MÉTODOS}

\section{Crescimento das plantas de arroz}

Sementes de arroz dos cultivares BR-Irga-409 e Labelle suscetíveis a $R$. solani foram esterilizadas em hipoclorito de sódio $10 \%(\mathrm{v} / \mathrm{v})$ por $2 \mathrm{~min}$, lavadas em água destilada por 3 min e colocadas para germinar em papel germiteste umedecido. Os rolos de papel germiteste foram colocados em câmara de germinação a $25^{\circ} \mathrm{C}$ por seis dias. As plântulas foram cultivadas em vasos plásticos com solução nutritiva diluída pela metade da concentração final por sete dias. Após esse período, as plantas foram transferidas para vasos plásticos contendo $5 \mathrm{~L}$ de solução nutritiva de Hoagland e ArNon (1950), com algumas modificações, constituída de: $1 \mathrm{mM} \mathrm{KNO}_{3} ; 0,25 \mathrm{mM} \mathrm{NH}_{4} \mathrm{H}_{2} \mathrm{PO}_{4} ; 0,1 \mathrm{mM} \mathrm{NH}_{4} \mathrm{Cl}$; $0,5 \mathrm{mM} \mathrm{MgSO} \cdot 7 \mathrm{H}_{2} \mathrm{O} ; 1 \mathrm{mM} \mathrm{Ca}\left(\mathrm{NO}_{3}\right)_{2} \cdot 4 \mathrm{H}_{2} \mathrm{O} ; 0,3 \mu \mathrm{M}$ $\mathrm{CuSO}_{4} .5 \mathrm{H}_{2} \mathrm{O} ; 0,33 \mu \mathrm{M} \mathrm{ZnSO}_{4} .7 \mathrm{H}_{2} \mathrm{O} ; 11,5 \mu \mathrm{M} \mathrm{H}_{3} \mathrm{BO}_{3}$; $3,5 \mu \mathrm{M} \mathrm{MnCl} .4 \mathrm{H}_{2} \mathrm{O} ; 0,014 \mu \mathrm{M}\left(\mathrm{NH}_{4}\right)_{6} \mathrm{Mo}_{7} \mathrm{O}_{2} .4 \mathrm{H}_{2} \mathrm{O}$; $25 \mu \mathrm{M} \mathrm{Na}_{2}$ EDTA; e $25 \mu \mathrm{M} \mathrm{FeSO}_{4} .7 \mathrm{H}_{2} \mathrm{O}$. O Si foi fornecido às plantas na forma de ácido monosilícico, o qual foi obtido pela passagem do silicato de potássio através de resina de troca de cátions (Amberlite IR-120B, $\mathrm{H}^{+}$forma, Sigma-Aldrich, São Paulo) (MA et al., 2002). As concentraçóes de Si utilizadas foram de $0 \mathrm{mM}$ e $2 \mathrm{mM}$. A soluçáo nutritiva foi trocada a cada quatro dias e o $\mathrm{pH}$ foi verificado a cada dois dias e mantido na faixa de 5,5 a 6 . 


\section{Inoculação das bainhas com $R$. solani e avaliação da doença}

As bainhas das folhas foram inoculadas com $R$. solani aos 60 dias após o transplantio (estádio de máximo perfilhamento) das plantas para a solução nutritiva. Utilizou-se o isolado de R. solani CNPAF Rs-1 (AG-1 IA). Escleródios do fungo foram preservados em sílica gel. Após o crescimento do fungo em meio de cultura batata-dextrose-ágar (BDA), obtido a partir de escleródios, transferiram-se discos do meio contendo micélio para novas placas de Petri contendo BDA. Na superfície do meio de cultura contido em cada placa de Petri, colocaram-se pedaços de palito de dente de aproximadamente $1 \mathrm{~cm}$ de comprimento, que serviram como suporte para o crescimento do fungo. Os pedaços de palito de dente foram previamente lavados em água quente, para remover possíveis substâncias tóxicas, colocados em frascos contendo BDA e autoclavados por 20 min (Rodrigues et al., 2001). As placas contendo micélio crescendo sobre e também no interior dos palitos permaneceram em câmara de crescimento $\left(25^{\circ} \mathrm{C}\right.$ e fotoperíodo de $12 \mathrm{~h} \mathrm{luz)}$ por cinco dias. No interior da segunda bainha do colmo principal de cada planta foi colocado, com auxílio de uma pinça estéril, um pedaço de palito colonizado pelo fungo. Para evitar a queda do palito de dente do interior da bainha, as bainhas inoculadas foram amarradas aos perfilhos das plantas com fitilhos. Imediatamente após a inoculação, as plantas foram transferidas para câmara de nevoeiro (temperatura de $25 \pm 2^{\circ} \mathrm{C}$ e umidade relativa de $90 \pm 5 \%)$. Avaliou-se o comprimento da lesão em cada bainha inoculada às 96 horas após inoculação (hai), com auxílio de um paquímetro digital. O comprimento relativo da lesão (CRL) foi calculado dividindo-se o comprimento da lesão pelo comprimento da bainha $\times 100$. O comprimento das bainhas foi padronizado em $15 \mathrm{~cm}$.

\section{Determinação da concentração de Si na bainha}

Após o término dos experimentos, as bainhas das plantas foram coletadas, secas em estufa a $65^{\circ} \mathrm{C}$ até atingirem peso constante e moídas em moinho tipo Wiley para determinaçáo da concentração de Si de acordo com KorndöRfER et al. (2004).

\section{Determinação das concentrações de lignina solúvel, insolúvel e total}

A segunda bainha do colmo principal das plantas das repetiçóes de cada tratamento foi coletada de plantas inoculadas (96 hai) ou não inoculadas (tratamento controle) $(0 \mathrm{~h}) \mathrm{com} R$. solani e armazenadas em ultrafreezer a $-80^{\circ} \mathrm{C}$. As concentraçóes de lignina solúvel e insolúvel foram determinadas de acordo com as metodologias descritas por GoldsCHMid (1971) e
Gomide e Demuner (1986). A concentraçáo da lignina total correspondeu ao somatório das concentraçóes de lignina solúvel e insolúvel. Foram obtidas duas amostras de bainhas de cada tratamento, cada qual composta por 10 bainhas. As bainhas foram trituradas em um micromoinho analítico e os fragmentos obtidos foram separados em peneiras de 40 mesh e de 60 mesh. Para a remoção de pigmentos, os fragmentos de bainha (2 $\mathrm{g}$ de material absolutamente seco) foram colocados no aparelho Soxhlet com $150 \mathrm{~mL}$ de acetona durante 16 ciclos de lavagens por quatro horas. Após a remoção do extrativo, os fragmentos foram colocados em estufa a $70^{\circ} \mathrm{C}$ por 12 horas, para volatilização da acetona. Um total de $300 \mathrm{mg}$ de fragmentos foram transferidos para tubos de ensaio e, em seguida, adicionaram-se $3 \mathrm{~mL}$ de ácido sulfúrico a $72 \%$. Os tubos de ensaio foram mantidos em banho-maria por uma hora, sob agitação contínua. A suspensão foi retirada de cada tubo de ensaio e colocada em frasco de vidro hermeticamente fechado contendo $84 \mathrm{~mL}$ de água destilada previamente adicionada. Esses frascos foram colocados em autoclave a $120^{\circ} \mathrm{C}$ por $1 \mathrm{~h}$. $\mathrm{O}$ extrato foi filtrado em cadinho de vidro sinterizado, o qual continha uma camada de $3 \mathrm{~mm}$ de óxido de alumínio previamente pesado. O filtrado foi guardado em geladeira para determinação da concentração de lignina solúvel. A lignina contida no cadinho foi lavada com água destilada quente até a completa remoção do ácido. O cadinho foi seco em estufa a $105^{\circ} \mathrm{C}$ até atingir peso constante, para aferição da massa. A concentração da lignina Klason insolúvel (LKI) foi determinada de acordo com a Equação 1:

$\mathrm{LKI}=\left(\frac{\text { peso do resíduo em gramas }}{\text { peso inicial da amostra em gramas }}\right) \times 100$

O filtrado da LKI foi transferido para balão volumétrico de $1 \mathrm{~L}$ cujo volume foi completado com água destilada. Em seguida determinou-se a absorção das amostras em espectrofotômetro (Evolution 300, ThermoScientific, New York, EUA) nos comprimentos de onda de $215 \mathrm{~nm}$ e $280 \mathrm{~nm}$. As determinaçôes das concentrações da lignina solúvel e insolúvel foram realizadas em triplicatas para cada tratamento. A concentração de lignina solúvel (CLS) foi determinada de acordo com a Equação 2:

$\mathrm{CLS}=\left(\frac{\left(4,538 \times \mathrm{Abs}_{215}\right)-\mathrm{Abs}_{280}}{300 \times \mathrm{P}}\right) \times 100$

\section{Determinação da concentração de açúcares totais}

Um volume de $20 \mu \mathrm{L}$ das amostras utilizadas para determinar-se a concentração de lignina solúvel e insolúvel nas repetiçóes de cada tratamento foi injetado em cromatógrafo iônico (DX 600 - Dionex, Sunnyvale, CA, EUA) com 
amostrador automático. Como fase estacionária, utilizou-se a coluna analítica CarboPac PA- $1(250 \times 4 \mathrm{~mm}$, Dionex). A temperatura de análise foi de $28^{\circ} \mathrm{C}$. Os monômeros de carboidratos foram eluídos com fase móvel composta de água ultrapura e $\mathrm{NaOH} 3 \mathrm{~mol} \mathrm{~L}^{-1}$ (99/1\%, v/v, respectivamente). O fluxo de eluiçáo foi de $1,0 \mathrm{~mL} \mathrm{~min}{ }^{-1}$. Para identificação dos compostos, comparou-se o tempo de retenção de cada composto com o de amostras padróes. Os padrōes utilizados foram glicose, manose, xilose e galactose, sendo o padrão interno a fucose. Todo o sistema cromatográfico foi controlado por meio do software Chromeleon (Dionex).

\section{Delineamento experimental e análise estatística dos dados}

O experimento foi instalado em delineamento inteiramente casualizado em esquema fatorial $2 \times 2 \times 2$ com quatro repetiçôes. Os fatores estudados foram dois cultivares de arroz, bainhas inoculadas ou não com $R$. solani e plantas supridas ou não com $\mathrm{Si}$. Cada repetição foi constituída por um vaso plástico contendo duas plantas de arroz. O experimento foi repetido e os dados de cada variável foram combinados depois de confirmada a homogeneidade de variância pelo teste de Bartlett. Os dados de cada variável foram submetidos à análise de variância e as médias foram comparadas pelo teste de Tukey (ocorrência de interação significativa) ao nível de 5\% de probabilidade. As análises estatísticas foram realizadas utilizando-se o programa SAS 9.0 (SAS Institute Inc., Cary, NC, USA).

\section{RESULTADOS E DISCUSSÃO}

Houve efeito significativo para os fatores cultivares e plantas supridas ou não com $\mathrm{Si}$, bem como para a interação desses fatores $(p \leq 0,05)$ para a concentraçáo de Si nas bainhas. $\mathrm{Na}$ presença de Si houve, nas bainhas das plantas dos cultivares Labelle e BR-Irga-409, um aumento de 77\% e $84 \%$, respectivamente, na concentração de $\mathrm{Si}$ em relação às das plantas não supridas com Si (Tabela 1). A concentração de Si nas bainhas das plantas do cultivar Labelle foi significativamente maior do que nas bainhas das plantas do cultivar BR-Irga-409, independentemente da presença ou ausência de Si na solução nutritiva. Rodrigues et al. (2001) observaram que plantas de arroz supridas com Si apresentaram um aumento de $80 \%$ na concentração de Si nas bainhas. Plantas como o arroz e a cana-de-açúcar chegam a acumular até 5 dag de Si por kg de matéria seca (Epstein, 1994). Apenas o fator plantas supridas ou não com $\mathrm{Si}$ foi significativo para o CRL. O CRL foi significativamente $(\mathrm{p}=0,002)$ menor (23\%) nas bainhas das plantas supridas com Si em relaçáo às bainhas das plantas não supridas com esse elemento (32,2\%). Rodrigues et al. (2001; 2003a,b) demonstraram que plantas de arroz supridas com Si apresentaram uma redução na severidade da queima das bainhas e na área abaixo da curva do progresso da extensão da lesão.

As concentraçóes de mananas, galactanas, arabinanas, xilanas e glucanas nas bainhas das plantas dos dois cultivares, inoculados ou não com $R$. solani, foi bem semelhante entre os tratamentos (Figura 1). Entretanto, para as plantas dos dois cultivares supridos com $\mathrm{Si}$ e inoculados com $R$. solani, a concentração de açúcares totais mostrou-se inferior quando comparada com a das plantas dos dois cultivares

Tabela 1. Concentração $\left(\mathrm{dag} \mathrm{kg}^{-1}\right)$ de silício $(\mathrm{Si})$ nas bainhas de plantas de arroz dos cultivares BR-Irga-409 e Labelle supridas $(+\mathrm{Si})$ ou não $(-\mathrm{Si})$ com $\mathrm{Si}$

\begin{tabular}{lcc}
\multicolumn{1}{c}{ Cultivares } & $\mathbf{- S i}$ & $+\mathbf{S i}$ \\
BR-Irga-409 & $0,52 \mathrm{aA}$ & $3,39 \mathrm{aB}$ \\
Labelle & $0,98 \mathrm{bA}$ & $4,32 \mathrm{bB}$ \\
\hline
\end{tabular}

Médias seguidas pela mesma letra, minúscula na coluna e maiúscula na linha, não diferem entre si pelo teste de Tukey ao nível de 5\% de significância
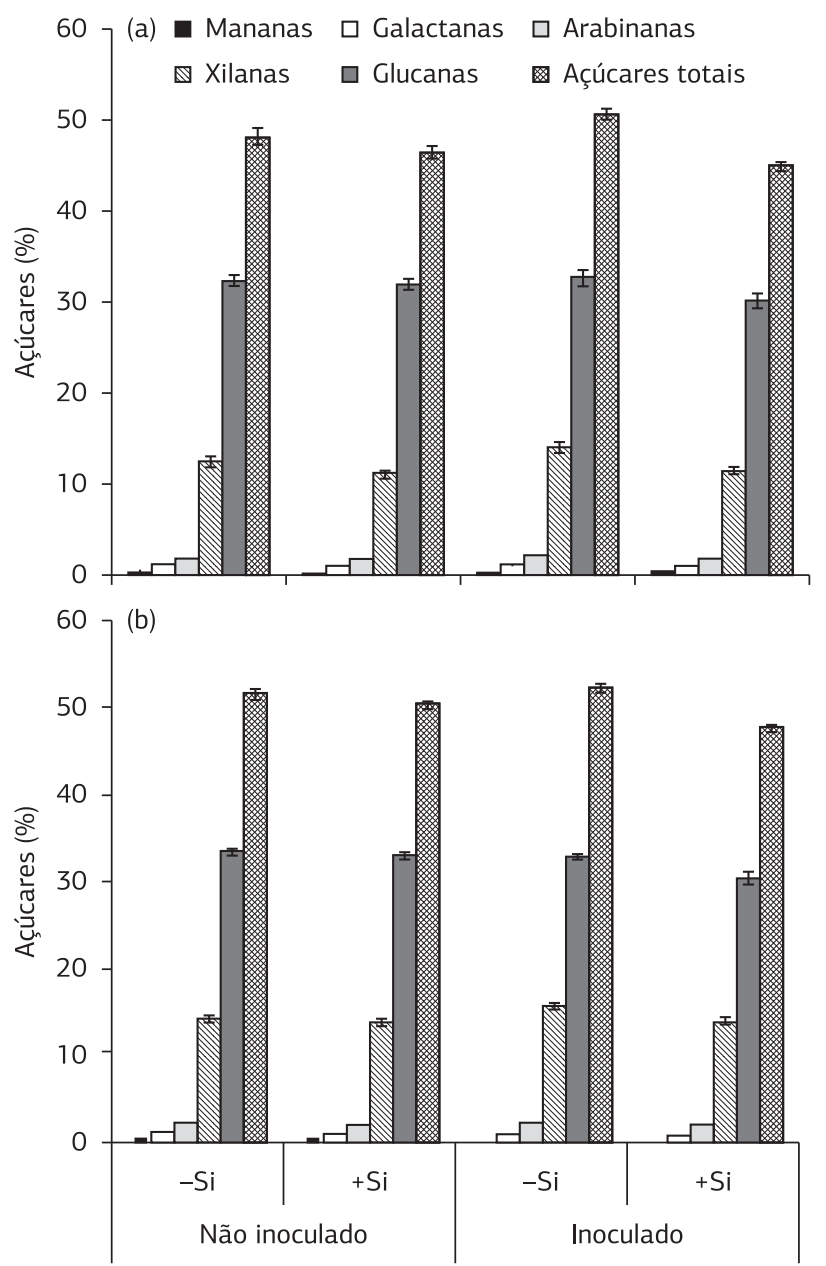

Figura 1. Concentraçóes de mananas, galactanas, arabinanas, xilanas e glucanas e de açúcares totais nas bainhas de plantas de arroz dos cultivares BR-Irga-409 (a) e Labelle (b) supridas $(+\mathrm{Si})$ ou não $(-\mathrm{Si})$ com silício (Si) e não inoculadas ou inoculadas com Rhizoctonia solani; o desvio padrão está representado em cada barra. 
não supridos com Si (Figura 1). Azuma e Koshimjima (1988), analisando bainhas de arroz livres de extrativos e despectinadas, encontraram $64 \%$ de carboidratos, sendo $80 \%$ de xilose, $13 \%$ de arabinose, $4,3 \%$ de glicose, $2,3 \%$ de galactose e $0,4 \%$ de manose. PrabHu et al. (2007) verificaram que as folhas de arroz com maior severidade de brusone foram as que apresentaram maior concentração de açúcares. Além disso, esses autores verificaram que o aumento nas doses de $\mathrm{Si}$ no solo resultou em uma menor concentração de açúcares nas folhas de arroz. Plantas de arroz com maior severidade da queima bacteriana, causada por Xanthomonas oryzae pv. oryzae, apresentaram maior concentração de açúcares (DATNOFF et al., 2007). Com o aumento na dose de $\mathrm{Si}$, houve uma redução na concentração de açúcares e, consequentemente, na severidade da queima bacteriana. Alteraçôes na concentração de carboidratos ocorrem quando as plantas sấo cultivadas em diferentes condiçôes nutricionais. Em geral, plantas com maior concentração de açúcares nos
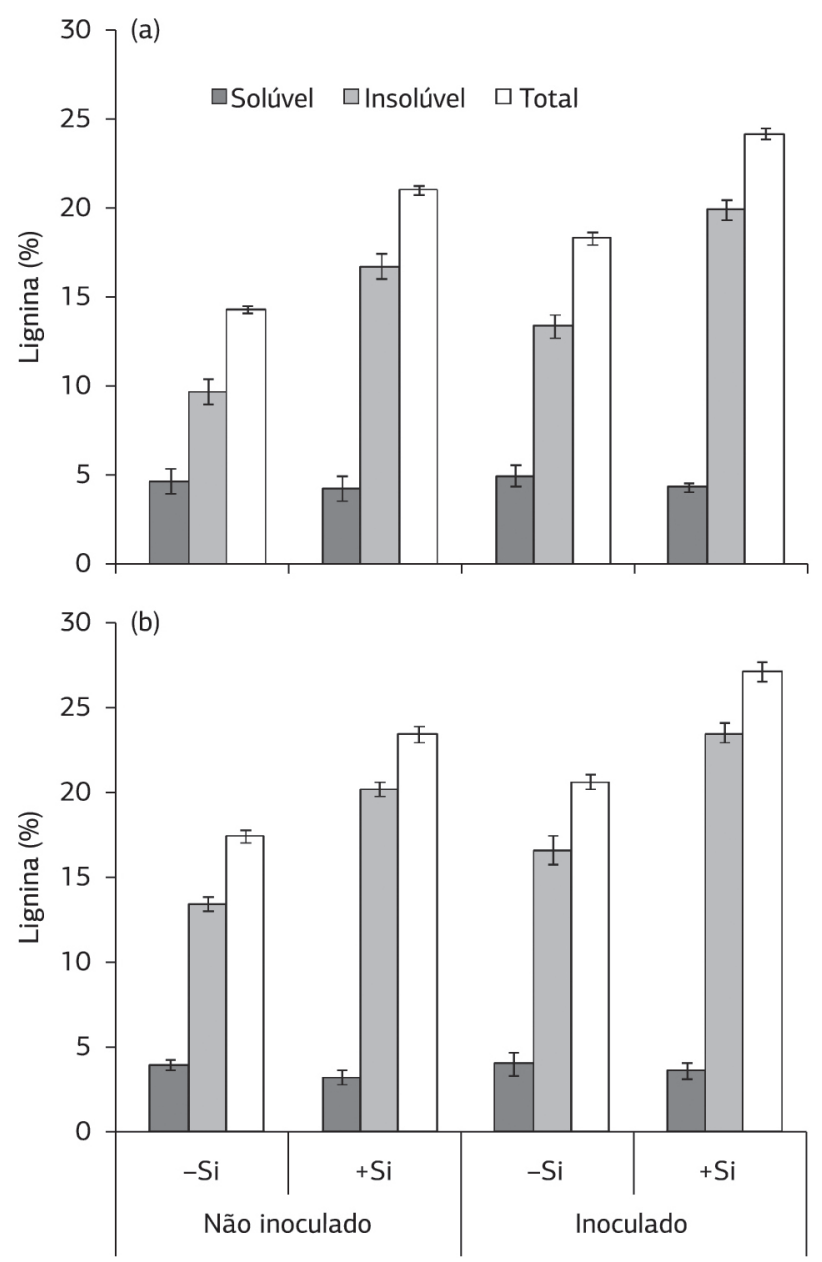

Figura 2. Concentração de lignina solúvel, insolúvel e total (solúvel + insolúvel) nas bainhas de plantas de arroz dos cultivares BR-Irga-409 (a) e Labelle (b) supridas $(+\mathrm{Si})$ ou não $(-\mathrm{Si})$ com silício $(\mathrm{Si})$ e não inoculadas ou inoculadas com Rhizoctonia solani; o desvio padrão está representado em cada barra. seus tecidos são mais suscetíveis à brusone (NotTEGHEM, 1981).

Para a concentração de lignina solúvel, insolúvel e total (Figura 2), observou-se que não houve variação entre os dois cultivares, independentemente de se as plantas foram supridas com $\mathrm{Si}$ e inoculadas com $R$. solani. Entretanto, comparaçóes entre as plantas supridas ou não com Si de qualquer um dos cultivares quando inoculados ou não com $R$. solani indicaram uma tendência de aumento nas concentraçôes de lignina insolúvel e total na presença de Si. Plantas de trigo supridas com Si apresentaram um aumento na concentração de lignina em resposta à infecção por Bipolaris sorokiniana (Domiciano et al., 2010). De acordo com Azuma e Koshimjima (1988), a concentração de lignina solúvel e insolúvel nas bainhas de arroz é da ordem de 5,6\% e 27\%, respectivamente. Plantas de trigo supridas com Si e inoculadas com Xanthomonas translucens pv. undulosa apresentaram uma menor concentração de lignina em comparação com plantas não supridas com $\mathrm{Si}$ e infectadas pela bactéria (SiLva et al., 2010). CAI et al. (2008) observaram que a concentração de lignina nas folhas das plantas de arroz supridas com Si não foi maior do que o observado nas folhas das plantas não supridas com esse elemento. Quando as plantas de arroz foram supridas com Si e inoculadas com Pyricularia grisea, a concentração de lignina aumentou em $36 \%$ em relação às plantas inoculadas não supridas com Si. Rodrigues et al. (2005) também encontraram aumento na concentração de lignina em folhas de plantas de arroz supridas com Si e inoculadas com $P$. grisea. Acredita-se que o Si esteja associado com um complexo lignina-carboidrato na parede celular das células da epiderme de folhas de arroz, o que pode, de certa forma, contribuir para uma maior lignificação da parede celular (INANAGA et al., 1995).

\section{CONCLUSÃO}

Plantas de arroz supridas com Si apresentaram redução nos sintomas da queima das bainhas devido ao aumento na lignificação dos tecidos das bainhas e diminuição na concentração de açúcares totais.

\section{AGRADECIMENTOS}

Os professores F. A. Rodrigues e J. L. Colodette agradecem ao Conselho Nacional de Desenvolvimento Científico e Tecnológico (CNPq) pelas bolsas de produtividade em pesquisa. O Dr. D. A. Schurt agradece a FAPEMIG pela bolsa de doutorado. Os autores agradecem a CAPES, CNPq e FAPEMIG pelos recursos financeiro. 


\section{REFERÊNCIAS}

AZUMA, J.; KOSHIMJIMA, T. Lignin-carbohydrate complexes from various sources. Methods in Enzymology, v.161, p.12-18, 1988. http://dx.doi.org/10.1016/0076-6879(88)61004-4

BEDENDO, I.P.; PRABHU, A.S. Doenças do arroz. In: KIMATI, H.; AMORIM, L.; REZENDE, J.A.M.; BERGAMIN FILHO, A.; CAMARGO, L.E.A. (Ed.). Manual de Fitopatologia - Doenças das Plantas Cultivadas. 4. ed. São Paulo: Campinas, Editora Agrônomica Ceres, 2005. v.2, p.79-90.

CAI, K.; GAO, D.; LUO, S.; ZENG, R.; YANG, J.; ZHU, X. Physiological and cytological mechanisms of silicon-induced resistance in rice against blast disease. Physiologia Plantarum, v.134, p.324333, 2008. PMid:18513376. http://dx.doi.org/10.1111/j.13993054.2008.01140.x

DALLAGNOL, L.J.; RODRIGUES, F.A.; MIELLI, M.V.B.; MA, J.F; DATNOFF, L.E.Defective active silicon uptake affects some components of rice resistance to brown spot. Phytopathology, v.99, p.116-121, 2009. PMid:19055443. http://dx.doi.org/10.1094/ PHYTO-99-1-0116

DATH, A.P. Sheath blight disease of rice and its management. New Delhi: Associated Publishing Company, 1990.

DATNOFF, L.E.; RODRIGUES, F.A.; SEEBOLD, K.W. Silicon and plant nutrition. In: DATNOFF, L.E.; ELMER, W.H.; HUBER, D.M. (Ed.). Mineral nutrition and plant disease. Saint Paul: American Phytopathological Society, 2007. p.233-246.

DOMICIANO, G.P.; RODRIGUES, F.A.; VALE, F.X.R.; XAVIERFILHA, M.S.; MOREIRA, W.R.; ANDRADE, C.C.L.; PEREIRA, S.C. Wheat resistance to spot blotch potentiated by silicon. Journal of Phytopathology, v.158, p.334-343, 2010. http://dx.doi. org/10.1111/j.1439-0434.2009.01623.x

EPSTEIN, E. The anomaly of silicon in plant biology. Proceedings of the National Academic Science USA, v.91, p.11-17, 1994. PMid:11607449 PMCid:PMC42876. http://dx.doi.org/10.1073/pnas.91.1.11

GOLDSCHMID, O. Ultraviolet spectra. In: SARKANEN, K.V.; LUDWIG, C.H. (Ed.). Lignins: occurrence, formation, structure and reactions. New York: John Wiley \& Sons, 1971. p.241-266.

GOMIDE, J.L.; DEMUNER, B.J. Determinação do teor de lignina na madeira: método Klason modificado. O Papel, v.47, p.36-38, 1986.

INANAGA, S.; OKASAKA, A.; TANAKA, S. Does silicon exist in association with organic compounds in rice plant? Japanese Journal of Soil Science and Plant Nutrition, v.11, p.111-117, 1995. http:// dx.doi.org/10.1080/00380768.1995.10419564

JIN, S.; CHEN, H. Structural properties and enzymatic hydrolysis of rice straw. Process Biochemical, v.41, p.1261-1264, 2006. http:// dx.doi.org/10.1016/j.procbio.2005.12.022

HATFIELD, R.; VERMERRIS, W. Lignin formation in plants. The dilemma of linkage specificity. Plant Physiology, v.126, p.13511357, 2001. PMid:11500535 PMCid:PMC1540132. http://dx.doi. org/10.1104/pp.126.4.1351

HON, D.N.S.; SHIRAISHI, N. Wood and cellulosic chemistry. 2nd ed. New York: Marcel Dekker, 2001.
HOAGLAND, D.R.; ARNON, D.I. The water culture method for growing plant without soil. California Agricultural Experiment Station Circular, v.347, p.1-32, 1950.

KIM, S.G.; KIM, K.W.; PARK, E.W.; CHOI, D. Silicon-induced cell wall fortification of rice leaves: A possible cellular mechanism of enhanced host resistance to blast. Phytopathology, v.92, p.1095-1103, 2002. PMid:18944220. http://dx.doi.org/10.1094/PHYTO.2002.92.10.1095

KORNDÖRFER, G.H.; PEREIRA, H.S.; NOLLA, A. Análise de Silício: Solo, Planta e Fertilizante. Uberlândia: Universidade Federal de Uberlândia, 2004. (Boletim Técnico 1).

MA, J.F.; TAMAI, K.; ICHII, M.; WU, G.F.A rice mutant defective in Si uptake. Plant Physiology, v.130, p.2111-2117, 2002. PMid:12481095 PMCid:PMC166723. http://dx.doi.org/10.1104/pp.010348

NOTTEGHEM, J.L. Cooperative experiment on horizontal resistance to rice blast. In: INTERNATIONAL RICE RESEARCH INSTITUTE. Blast and upland rice: report and recommendations from the meeting for international collaboration in upland rice improvement. Los Bańos: IRRI, 1981. p.43-51.

OU, S.H. Rice Diseases. 2nd ed. England: Kew, Surrey, Commonwealth Mycological Institute, 1985.

PRABHU, A.S.; SANTOS, A.B.; DIDONET, A.D. Soluble tissue sugar content and leaf blast severity in response to the application of calcinated serpentinite as a silicon source in irrigated rice. Summa Phytopathologica, v.33, p.402-404, 2007. http://dx.doi.org/10.1590/ S0100-54052007000400014

RODRIGUES, F.A.; DATNOFF, L.E.; KORNDÖRFER, G.H.; SEEBOLD, K.W.; RUSH, M.C. Effect of silicon and host resistance on sheath blight development in rice. Plant Disease, v.85, p.827832, 2001. http://dx.doi.org/10.1094/PDIS.2001.85.8.827

RODRIGUES, F.A.; VALE, F.X.R.; KORNDÖRFER, G.H.; DATNOFF, L.E.; OLIVEIRA, A.M.; ZAMBOLIM, L. Influence of silicon on sheath blight of rice in Brazil. Crop Protection, v.22, p.23-29, 2003a. http://dx.doi.org/10.1016/S0261-2194(02)00084-4

RODRIGUES, F.A.; VALE, F.X.R.; DATNOFF, L.E.; PRABHU, A.S.; KORNDÖRFER, G.H. Effect of rice growth stages and silicon on sheath blight development. Phytopathology, v.93, p.256-261, 2003 b. PMid:18944334. http://dx.doi.org/10.1094/PHYTO.2003.93.3.256

RODRIGUES, F.A.; JURICK, W.M.; DATNOFF, L.E.; JONES, J.B.; ROLLINS, J.A. Silicon influences cytological and molecular events in compatible and incompatible rice-Magnaporthe grisea interactions. Physiological and Molecular Plant Pathology, v.66, p.144-159, 2005. http://dx.doi.org/10.1016/j.pmpp.2005.06.002

RUSH, M.C.; LEE, F.N. Sheath blight. In: WEBSTER, R.K.; GUNNELL, P.S. (Ed.). Compendium of Rice Diseases. St. Paul: American Phytopathological Society, 1992. p.22-23.

SANGSTER, A.G.; HODSON, M.J.; TUBB, H.J. Silicon deposition in higher plants. In: DATNOFF, L.E.; SNYDER, G.H.; KORNDÖRFER, G.H. (Ed.). Silicon in Agriculture. Amsterdam: Elsevier, 2001. 424p. http://dx.doi.org/10.1016/S0928-3420(01)80009-4

SCHURT, D.A.; RODRIGUES, F.A.; REIS, R.D.; MOREIRA, W.R.; SOUZA, N.F.A.; SILVA, W.A. Resistência física de bainhas de plantas de arroz supridas com silício e infectadas por Rhizoctonia 
solani. Tropical Plant Pathology, v.37, p.281-285, 2012. http://dx.doi. org/10.1590/S1982-56762012000400008

SILVA, I.T.; RODRIGUES, F.A.; OLIVEIRA, J.R.; PEREIRA, S.C.; ANDRADE, C.C.L.; SILVEIRA, P.R.; CONCEIÇÃO, M.M. Wheat resistance to bacterial leaf streak mediated by silicon. Journal of Phytopathology, v.158, p.253-262, 2010. http://dx.doi.org/10.1111/ j.1439-0434.2009.01610.x

SMEEKENS, S. Sugar-induced signal transduction in plants. Annual Review of Plant Physiology and Plant Molecular Biology, v.51, p.4981, 2000. PMid:15012186. http://dx.doi.org/10.1146/annurev. arplant.51.1.49

SUMMERS, M.D.; JENKINS, B.M.; HYDE, P.R.; WILLIAMS, J.F.; MUTTERS, R.G.; SCARDACCI, S.C. Biomass production and allocation in rice with implications for straw harvesting and utilization. Biomass and Bioenergy, v.24, p.163-173, 2003. http:// dx.doi.org/10.1016/S0961-9534(02)00132-0

VANDERPLANK, J.E. Sink-induced loss of resistance. In: VANDERPLANK, J.E. (Ed.). Diseases Resistance in Plants. 2nd ed. Academic Press, 1984. http://dx.doi.org/10.1016/B978-0-12-711442$2.50015-5$

VIDHYASEKARAN, P. Sugars and Diseases Resistance. In: VIDHYASEKARAN, P. (Ed.). Physiology of Diseases Resistance in Plants. CRC Press, 1988.

YOSHIDA, S.; OHNISHI, Y.; KITAGISHI, K. Chemical forms, mobility and deposition of silicon in rice plant. Soil Science and Plant Nutrition, v.8, p.15-21, 1962. http://dx.doi.org/10.1080/003 80768.1962.10430992 